\title{
Investigation on the Distribution of Common Thalassemias in Various Cities and Counties under the Jurisdiction of Chongzuo City, Guangxi
}

\author{
Huan Zhao*\#, Yan Chen*, Jing Lan, Liuxian Huang, Tianyou Huang, Miaohong Li, \\ Xingchuang Chen, Wanwei Yang, Fu Huang, Tongfeng Huang, Xiuge Li
}

Inspection Department of Chongzuo Maternal and Child Health Care Hospital, Chongzuo, China

Email:"122610256@qq.com

How to cite this paper: Zhao, H., Chen, Y., Lan, J., Huang, L.X., Huang, T.Y., Li, M.H., Chen, X.C., Yang, W.W., Huang, F., Huang, T.F. and Li, X.G. (2021) Investigation on the Distribution of Common Thalassemias in Various Cities and Counties under the Jurisdiction of Chongzuo City, Guangxi. Advances in Bioscience and Biotechnology, 12, 361-370.

https://doi.org/10.4236/abb.2021.1211023

Received: September 29, 2021

Accepted: November 2, 2021

Published: November 5, 2021

Copyright $\odot 2021$ by author(s) and Scientific Research Publishing Inc. This work is licensed under the Creative Commons Attribution International License (CC BY 4.0).

http://creativecommons.org/licenses/by/4.0/

\begin{abstract}
Objective: To understand the distribution of thalassemia in all districts under the jurisdiction of Chongzuo City. Methods: Collect blood routine indicators from May 2014 to 31 December 2020 in the districts of this city to screen out suspected Mediterranean patients for genetic diagnosis; GGAP-PCR and PCR-reverse dot hybridization were used to analyze the thalassemia gene in the specimens of suspected patients; compare the prevalence of thalassemia in the counties and cities within the jurisdiction of this city, and provide corresponding medical advice to the health authorities. Results: 21,535 venous blood specimens from patients with suspected thalassemia were collected in the city. There were 14,215 positive cases of thalassemia, accounting for $66.01 \%$ of the total number of patients, among which 9455 cases $(43.91 \%)$ were pure $\alpha$ gene positive. 3464 patients (16.09\%) were positive for simple $\beta$ gene. 1296 patients (6.02\%) were positive for $\alpha \beta$ double gene. The proportions of thalassemia gene testing for $\alpha$-thalassaemia gene, $\beta$-thalassaemia gene, and $\alpha-\beta$ double gene in various counties and districts were different. According to the multiple rate or the chi-square test of the constituent ratio, the comparison of the distribution of the thalassaemia gene test results in each area, $\chi^{2}=472.6917, \mathrm{P}=0.0000$, the difference is statistically significant. Conclusion: Severe thalassemia is a tragedy for a family. It not only needs to spend a lot of money to prolong life, but it also cannot change the situation of losing life and financial emptiness in the end. It is suggested that timely screening, timely diagnosis and medical consultation should be carried out in married and unborn families and early pregnancy, so as to reduce the birth of children with severe thalassemia and avoid the occurrence of tragedies.
\end{abstract}




\section{Keywords}

Thalassemia, $\alpha$-Thalassaemia Gene, $\beta$-Thalassaemia Gene, Distribution Status, Gene Analysis

\section{Background Introduction}

Thalassemia is a relatively rare congenital anemia disease. Thalassemia is divided into four types: $\alpha, \beta, \delta \beta$ and $\delta$, among which $\alpha$ and $\beta$-thalassemia are more common [1] [2] [3] [4]. The disease is widely distributed in many parts of the world, and Southeast Asia is one of the high-incidence areas. It is more common in Guangdong, Guangxi, and Sichuan in my country; Sporadic cases are found in provinces south of the Yangtze River, and rare in the north [5] [6]. According to reports, the incidence in Guangxi: $\alpha$-thalassemia $17.5 \%, \beta$-thalassemia: $6.43 \%$ [7] [8] [9]. Chongzuo City currently has no relevant statistics. In patients with this symptom, the bead protein chain in the body will be insufficient or even lacking, which will directly cause the structure of human hemoglobin to change, which will affect the carrying capacity of the normal oxygen and cause functional impairment such as liver and spleen [10] [11] [12] [13]. At present, there is no medical method to treat the disease. Therefore, patients with severe thalassemia often die unfortunately in infants and young children, but this disease can still be effectively prevented [14]-[19]. Therefore, in terms of marriage, doctors provide medical advice to patients with positive family history; While, premarital examination and prenatal genetic diagnosis of the fetus, and prenatal diagnosis using genetic analysis can diagnose severe $\alpha$ and $\beta$-thalassaemia fetuses during pregnancy. The timely termination of pregnancy to avoid the occurrence of fetal oedema syndrome and the birth of patients with severe $\beta$-thalassemia is currently an effective method to prevent this disease [20] [21] [22]. Therefore, carrying out population census and genetic counseling are of great significance to the prevention of this disease. In order to understand the distribution of thalassemia in various cities and counties of Chongzuo City, this study selected samples from various cities and counties from May 2014 to December 2020 for genetic testing. The results are now reported as follows.

\section{Materials and Methods}

\subsection{Research Subjects}

This study intends to use the method of case-control analysis to conduct thalassemia gene analysis on 21,535 venous blood samples of patients suspected of thalassemia through routine blood screening collected from May 1, 2014 to December 31, 2020. All cases are signed and confirmed with the consent of the patient or guardian, and will be implemented after discussion and approval by the Medical Ethics Committee of this hospital. 


\subsection{Screening Method}

The venous blood of the patient shall be screened according to the requirements of blood routine, blood type and hemoglobin electrophoresis. Any abnormality shall be tested for thalassaemia gene according to the doctor's recommendation. If one party is diagnosed with thalassaemia, even if the screening result of the other party is normal, the genetic test of the same type of thalassaemia is required. If both parties are carriers of the same type of thalassemia gene, amniocentesis will be performed for genetic prenatal diagnosis from 16 to 24 weeks of gestation.

\subsection{Gene Detection Method}

Genetic testing of deletion $\alpha$-thalassemia was performed by GAP-PCR (--SEA, $-\alpha^{3.7},-\alpha^{4.2}$ etc.). Mutations in the non-deletion $\alpha$-thalassemia gene ( $\alpha^{\mathrm{CS}}, \alpha^{\mathrm{WS}}$ etc.) and $\beta$-thalassemia gene were tested by PCR-reverse point hybridization.

\subsection{Interpretation of the Results of Thalassaemia Genetic Testing}

2.4.1. Interpretation of Test Results for Deletion of $\alpha$-Thalassaemia Gene
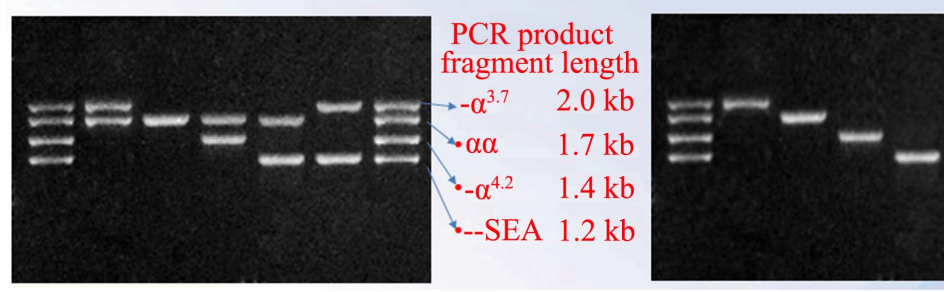

M DNA Markers Result judgment
1) $\alpha \alpha /-\alpha^{3.7}$ Heterozygote
2) $\alpha \alpha / \alpha \alpha$ Normal
3) $\alpha \alpha /-\alpha^{4.2}$ Heterozygote
4) $\alpha \alpha /-{ }^{\text {SEA }}$ Heterozygote
5) $-\alpha^{3.7} /-{ }^{\text {SEA }}$ Double heterozygote
6) $-\alpha^{3.7} /-\alpha^{3.7}$ Homozygous
7) $\alpha \alpha / \alpha \alpha$ Normal
8) $-\alpha^{4.2} /-\alpha^{4.2}$ Homozygous
9) --SEA/--SEA Homozygous

\subsubsection{Interpretation of the Results of Non-Missing $\alpha$-Thalassaemia}

\begin{tabular}{|c|c|c|}
\hline SN & $\mathrm{CSN} \bigcirc$ & ¿WSN \\
\hline 5 & $\mathrm{CSM}$ & ¿WS \\
\hline
\end{tabular}

\begin{tabular}{|c|c|c|c|}
\hline QSN & CSN & WSNO & \\
\hline SM & CSM & $\vdots \mathrm{W}$ & \\
\hline
\end{tabular}

Genotype: $\alpha^{\mathrm{QS}} \alpha / \alpha \alpha$ (Three deletion types of $\alpha$ Thalassemia were detected as $\alpha \alpha / \alpha \alpha)$

Genotype: $\alpha^{\mathrm{QS}} \alpha /$--SEA (Three deletion types of $\alpha$ Thalassemia were detected as $\alpha \alpha /--$ SEA) 


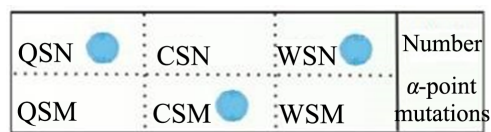

Genotype: $\alpha^{\mathrm{CS}} \alpha /$--SEA (Three deletion types of $\alpha$ thalassemia were detected as $\alpha \alpha /$--SEA)

\begin{tabular}{|c|c|c|}
\hline QSN & CSN & ¿WSN \\
\hline QSM & CSM & WS \\
\hline
\end{tabular}

Genotype: $-\alpha^{4.2} /--\mathrm{SEA} ;-\alpha^{3.7} /-\alpha^{4.2} ; \alpha^{3.7} /-\alpha^{4.2}$;

$-\alpha^{4.2} /-\alpha^{4.2} ;-\alpha^{3.7} /-\alpha^{3.7} ;--\mathrm{SEA} /--\mathrm{SEA}$

\subsubsection{Interpretation of $\beta$-Thalassemia Gene Diagnosis Results}

\begin{tabular}{|c|c|c|c|c|c|c|c|}
\hline $41-42 \mathrm{~N}$ & $654 \mathrm{~N}$ & $-28 \mathrm{~N}$ & $71-72 \mathrm{~N}$ & $17 \mathrm{~N}$ & $\beta \mathrm{EN}$ & $31 \mathrm{~N}$ & $27 / 28 \mathrm{M}$ \\
\hline $41-42 \mathrm{M}$ & $654 \mathrm{M}$ & $-28 \mathrm{M}$ & $71-72 \mathrm{M}$ & $17 \mathrm{M}$ & $\beta \mathrm{EM}$ & $31 \mathrm{M}$ & IVS1-1M \\
\hline $43 \mathrm{M}$ & $-32 \mathrm{M}$ & $-29 \mathrm{M}$ & $-30 \mathrm{M}$ & $14-15 \mathrm{M}$ & $\mathrm{CAPM}$ & IntM & IVS1-5M \\
\hline
\end{tabular}

\begin{tabular}{|c|c|c|c|c|c|c|c|c|c|}
\hline $41-42 \mathrm{~N}$ & $654 \mathrm{~N}$ & $28 \mathrm{~N}$ & $71-72 \mathrm{~N}$ & $17 \mathrm{~N}$ & $\beta E N$ & $31 \mathrm{~N}$ & $27 / 28 \mathrm{M}$ & \multirow{2}{*}{$654 \mathrm{M} / 71-72 \mathrm{M}$} & \multirow{2}{*}{ Double heterozygote } \\
\hline $41-42 \mathrm{M}$ & $654 \mathrm{M}$ & $28 \mathrm{M}$ & $71-72 \mathrm{M}$ & $17 \mathrm{M}$ & $\beta \mathrm{EM}$ & $31 \mathrm{M}$ & IVS1-1M & & \\
\hline $43 \mathrm{M}$ & $32 \mathrm{M}$ & $29 \mathrm{M}$ & $30 \mathrm{M}$ & $14-15 \mathrm{M}$ & CAP & IntM & IVS1-5M & \multirow{4}{*}{$\mathrm{N} / \mathrm{N}$} & \multirow{5}{*}{ Normal } \\
\hline $41-42 \mathrm{~N}$ & $654 \mathrm{~N}$ & $28 \mathrm{~N}$ & $71-72 \mathrm{~N}$ & $17 \mathrm{~N}$ & $\beta \mathrm{EN}$ & $31 \mathrm{~N}$ & $27 / 28 \mathrm{M}$ & & \\
\hline $41-42 \mathrm{M}$ & $654 \mathrm{M}$ & $28 \mathrm{M}$ & $71-72 \mathrm{M}$ & $17 \mathrm{M}$ & $\beta \mathrm{EM}$ & $31 \mathrm{M}$ & IVS1-1M & & \\
\hline $43 \mathrm{M}$ & $32 \mathrm{M}$ & $29 \mathrm{M}$ & $30 \mathrm{M}$ & $14-15 \mathrm{M}$ & CAP & IntM & IVS1-5M & & \\
\hline $41-42 \mathrm{~N}$ & $654 \mathrm{~N}$ & $28 \mathrm{~N}$ & $71-72 \mathrm{~N}$ & $17 \mathrm{~N}$ & $\beta \mathrm{EN}$ & $31 \mathrm{~N}$ & $27 / 28 \mathrm{M}$ & \multirow{3}{*}{$\beta \mathrm{EM} / \beta \mathrm{EM}$} & \\
\hline $41-42 \mathrm{M}$ & $654 \mathrm{M}$ & $28 \mathrm{M}$ & $71-72 \mathrm{M}$ & $17 \mathrm{M}$ & $\beta E M$ & $31 \mathrm{M}$ & IVS1-1M & & \multirow[t]{2}{*}{ Homozygous } \\
\hline $43 \mathrm{M}$ & $32 \mathrm{M}$ & $29 \mathrm{M}$ & $30 \mathrm{M}$ & $14-15 \mathrm{M}$ & CAP & IntM & IVS1-5M & & \\
\hline $41-42 \mathrm{~N}$ & $654 \mathrm{~N}$ & $28 \mathrm{~N}$ & $71-72 \mathrm{~N}$ & $17 \mathrm{~N}$ & $\beta \mathrm{EN}$ & $31 \mathrm{~N}$ & $27 / 28 \mathrm{M}$ & \multirow{3}{*}{$41-42 \mathrm{M} / \mathrm{N}$} & \multirow{3}{*}{ Heterozygote } \\
\hline $41-42 \mathrm{M}$ & $654 \mathrm{M}$ & $28 \mathrm{M}$ & $71-72 \mathrm{M}$ & $17 \mathrm{M}$ & $\beta \mathrm{EM}$ & $31 \mathrm{M}$ & IVS1-1M & & \\
\hline $43 \mathrm{M}$ & $32 \mathrm{M}$ & $29 \mathrm{M}$ & $30 \mathrm{M}$ & $14-15 \mathrm{M}$ & CAP & IntM & IVS1-5M & & \\
\hline
\end{tabular}

\subsection{Instruments and Reagents}

The nucleic acid extractor adopts the nucleic acid extractor Lab-Aid820 and Lab-Aid824s produced by Xiamen Zhishan; the thermal cycler adopts the T100 type produced by Bo Le; the electrophoresis instrument adopts the Bio-rad electrophoresis instrument produced by Bo Le; Hybridization instrument adopts YN-H96 automatic nucleic acid molecular hybridization instrument produced by Yaneng Biological Company. The reagents use the supporting reagents of the corresponding equipment. All reagents are used within the validity period; they participate in the quality evaluation activities of the National Clinical Laboratory Center every year, and all items are qualified.

\subsection{Statistical Analysis}

The SPSS22.0 statistical software was used for statistical analysis; the statistics of counting units used the chi-square test; the statistics of measurement units used the $t$ test, and $\mathrm{P}<0.05$ was considered statistically significant.

\section{Results}

Venous blood samples collected from outpatients and inpatients in our hospital from 2014 to 2020 and sent from counties and districts to test for thalassemia 
genes, a total of 21,535 cases, including 6148 cases in Jiangzhou District (including our hospital), and there are 2318 cases of alpha-thalassemia gene positive, accounting for $37.70 \%$ of the people screened, 896 cases were positive for $\beta$-thalassaemia gene, accounting for $14.57 \%$ of the people screened, 464 cases were positive for $\alpha \beta$ double gene, accounting for $7.55 \%$ of the people screened. 2470 cases were negative, accounting for $40.18 \%$ of the screened population; 2852 cases in Daxin County, and 1337 cases were positive for $\alpha$-thalassaemia gene, accounting for $46.88 \%$ of the screened population, and 457 cases were positive for $\beta$-thalassaemia gene, accounting for screened $16.02 \%$ of the people checked; 175 cases were positive for both $\alpha$ and $\beta$; accounted for $6.14 \%$ of the screened persons, and 883 were negative, accounting for $30.96 \%$ of the screened persons. 3291 cases in Fusui County, 1372 cases were positive for $\alpha$-thalassaemia gene, and accounting for $41.69 \%$ of the screened population; 456 cases were positive for $\beta$-thalassaemia gene, and accounting for $13.86 \%$ of the screened population, 125 cases were positive for $\alpha \beta$; accounting for $3.79 \%$ of the screened population, and 1338 cases were negative, accounting for $40.66 \%$ of the people examined. 2354 cases in Tiandeng County; 1144 cases were positive for the $\alpha$-thalassaemia gene, and accounting for $48.60 \%$ of the screened people; 430 cases were positive for the $\beta$-thalassaemia gene, and accounting for $18.27 \%$ of the screened people; 109 cases were positive for both $\alpha$ and $\beta$-thalassaemia which accounted for $4.63 \%$ of the screened population; 671 were negative, and accounted for $28.50 \%$ of the screened population. There were 3249 cases in Longzhou County, and 1465 cases were positive for $\alpha$-thalassaemia gene, accounting for $45.09 \%$ of the screened population; 512 cases were positive for $\beta$-thalassaemia gene, accounting for $15.76 \%$ of the screened population; $\alpha$ and $\beta$ were positive for all cases. 187 cases, accounting for $5.75 \%$ of the screened population, 1085 cases were negative, accounting for $33.40 \%$ of the screened population. There are 2507 cases in Ningming County, 1234 cases were positive for $\alpha$-thalassaemia gene, accounting for $49.22 \%$ of the screened population; 491 cases were positive for $\beta$-thalassaemia gene, accounting for $19.59 \%$ of the screened population, and 157 cases were positive for $\alpha$ and $\beta$, accounting for $6.26 \%$ of the screened population, and 625 negative cases, accounting for $24.93 \%$ of the screened population. There were 1134 cases in Pingxiang City, 585 cases were positive for $\alpha$-thalassaemia gene, accounting for $51.59 \%$ of the screened persons, 222 cases were positive for $\beta$-thalassaemia gene, accounting for $19.58 \%$ of the screened persons, and 79 were positive for $\alpha$ and $\beta$ which accounting for $6.96 \%$ of the screened population, 248 negative cases, and accounting for $21.87 \%$ of the screened population. According to the chi-square test of multiple rate or composition ratio, the comparison of the distribution of the thalassaemia gene test results in each city and county, $\chi^{2} \mathrm{P}=0.0000$, the difference is statistically significant. See Table 1 below for details.

\section{Discussion}

Thalassemia is a relatively rare congenital anemia disease. In terms of the 
Table 1. Distribution of the results of thalassaemia gene testing in each district of Chongzuo City.

\begin{tabular}{cccccccccc}
\hline District & Cases & $\begin{array}{c}\text { Positive } \\
\alpha \text { genes }\end{array}$ & $\begin{array}{c}\text { Proportion } \\
(\%)\end{array}$ & $\begin{array}{c}\text { Positive } \\
\beta \text { genes }\end{array}$ & $\begin{array}{c}\text { Proportion } \\
(\%)\end{array}$ & $\begin{array}{c}\text { Positive } \alpha \beta \\
\text { double gene }\end{array}$ & $\begin{array}{c}\text { Proportion } \\
(\%)\end{array}$ & $\begin{array}{c}\text { Negative } \\
\text { Proportion } \\
(\%)\end{array}$ \\
\hline $\begin{array}{c}\text { Jiangzhou District } \\
\text { (including this } \\
\text { hospital) }\end{array}$ & 6148 & 2318 & 37.70 & 896 & 14.57 & 464 & 7.55 & 2470 & 40.18 \\
$\begin{array}{c}\text { Daxin County } \\
\text { Fusui County }\end{array}$ & 2852 & 1337 & 46.88 & 457 & 16.02 & 175 & 6.14 & 883 & 30.96 \\
Tiandeng County & 2354 & 1144 & 48.60 & 430 & 18.27 & 109 & 4.63 & 671 & 28.50 \\
Longzhou County & 3249 & 1465 & 45.09 & 512 & 15.76 & 187 & 5.76 & 1085 & 33.39 \\
Ningming County & 2507 & 1234 & 49.22 & 491 & 19.59 & 157 & 6.26 & 625 & 24.93 \\
Pingxiang City & 1134 & 585 & 51.59 & 222 & 19.58 & 79 & 6.97 & 248 & 21.87 \\
$\quad$ Total & 21,535 & 9455 & 43.91 & 3464 & 16.09 & 1296 & 6.02 & 7320 & 33.99 \\
\hline
\end{tabular}

Note: According to the comparison of multiple rate or composition ratio, $\chi^{2}=472.6917, \mathrm{P}=0.0000$.

prevalence in my country, it is more common in the south. In patients with this symptom, the globin chain in the body will be insufficient or even lacking, which will directly cause the structure of human hemoglobin to change, which will affect the normal oxygen carrying capacity and cause damage to functions such as liver and spleen [23] [24] [25] [26]. Generally speaking, if two thalassemia patients with the same type married, there is a chance of giving birth to severe anemia patients. To effectively prevent the disease, blood is required for genetic analysis. If it is confirmed that they belong to type $\beta$, the children will have a fourth chance of being completely normal, a second chance of becoming mild anemia, and a fourth chance of becoming medium or severe anemia [27] [28].

In view of the lack of radical cure for the disease and poor clinical manifestations of moderate and severe prognosis, doctors should make medical advice to patients with positive family history or marriage, and conduct premarital examination and prenatal genetic diagnosis during early pregnancy, to avoid the occurrence of the next generation of children.

Medthalassaemia is completely preventable, and the key is early screening for genetic carriers. According to reports, one out of every nine people in Guangdong carries the thalassaemia gene. Some Cantonese people have a long-term bad complexion, which may be the cause of mild thalassaemia. They have almost no symptoms and can be regarded as normal people and do not need treatment. However, if both husband and wife are carriers of the thalassaemia gene, they may give birth to severe thalassaemia children [29] [30] [31] [32] [33]. Therefore, it is very important to screen for thalassaemia before pregnancy. The easiest thing is to do a routine blood test during the premarital examination or pregnancy examination. If the wife's average hemoglobin volume (MCV) is lower than the normal value, she may be a carrier of the thalassemia gene, and the husband should also go to the hospital for examination as soon as possible. 
Those who have thalassemia in the family, have had a stillbirth, and both spouses have low MVC are all high-risk groups of thalassemia. In addition to routine blood tests, hemoglobin electrophoresis screening and genetic diagnosis should also be done. Even if there is no premarital examination and pregnancy check, and the pregnant woman is found to be a carrier of the thalassaemia gene during the prenatal screening, it can still prevent the crisis from happening. The spouse of a pregnant woman should go to the hospital for examination as soon as possible. If both parties are found to be carriers of the same type of thalassaemia gene, the fetus has a $1 / 4$ chance of being normal, and a $1 / 2$ chance of being a gene carrier (that is, thalassaemia mild). There is a $1 / 4$ chance of being severe thalassaemia. Next, the prenatal genetic diagnosis can be performed for the fetus in the pregnant woman's abdomen by drawing amniotic fluid or umbilical cord blood. If the genetic diagnosis finds that the fetus is normal or thalassaemia mild, the pregnancy can be continued. If the fetus is found to have thalassaemia intermediate or severe, the doctor will advise the pregnant woman to terminate the pregnancy [34] [35] [36].

In accordance with the principle of "check everything", this study provides citizens with thalassemia genetic testing to reduce the birth of children with severe thalassemia in Chongzuo City; Block new cases to reduce the burden of treatment, and prevent poverty caused by illness. Grasp the incidence and distribution of the $\alpha$ and $\beta$ thalassemia in this city. Form evaluation conclusions and put forward medical guidance opinions. To provide to the health authorities for better prevention and control of thalassemia in their jurisdiction.

Results of this study showed that among 21,535 suspected thalassemia samples collected, $9455 \alpha$ gene deletion or point mutation were screened by genetic diagnosis, accounting for $43.91 \%$ of the total screened. 3464 cases were point mutations in the $\beta$ gene, accounting for $16.09 \%$ of the total screening; 1296 cases with positive $\alpha \beta$ genes, accounting for $6.02 \%$; 7320 negative cases, accounting for $33.99 \%$; the total number of positive cases was 14,215 , accounting for $66.01 \%$ of the total screening population. From this result, it can be seen that the incidence of thalassemia is still relatively high in all cities and counties under the jurisdiction of Chongzuo City, which should arouse the attention of relevant departments. In addition, the incidence of thalassemia varies from city to county in Chongzuo City. According to the comparison of multi-rate or composition ratio, the incidence of thalassemia in each city and county has a significant difference, $\mathrm{P}<0.001$. This requires that we must pay attention to supervision, and guide relevant departments to prevent and treat diseases based on key inspections in key areas to reduce the incidence of thalassemia as much as possible, and give the next generation a healthy body.

\section{Conclusion}

The results of this study showed that the incidence of thalassemia in the gene detection results of suspected thalassemia samples in Chongzuo city was high, up to $66.01 \%$, which should be paid close attention by relevant departments. In 
addition, the incidence of thalassemia was unbalanced among cities, counties and districts of Chongzuo city, and the comparison of multiple rates or constituent ratios was $\mathrm{P}<0.001$, which required the relevant health authorities to have targeted supervision to achieve the purpose of disease prevention and treatment. Thalassemia major is a tragedy for a family, requiring a lot of money to prolong life, and ultimately failing to change the situation. It is suggested to timely screening, timely diagnosis and medical consultation in married childless families and early pregnancy to reduce the birth of children with severe thalassaemia and avoid the occurrence of tragedy.

\section{Limitations of the Study}

The source of the cases in this study is only in Chongzuo City, Guangxi. The results of the study only represent the situation in Chongzuo area, and cannot represent the situation in other regions or the whole country, which has certain limitations.

\section{Acknowledgements}

In the research process of this subject, we have received strong support and help from many departments and individuals, as well as other researchers who did not participate in this subject. Here, all the members participating in this research express their deepest gratitude and wish them good health and all the best.

\section{Fund Project}

Scientific Research and Technology Development Project of Chongzuo City, Guangxi (NO. Chongke Attack 17122603).

\section{Conflicts of Interest}

The authors declare no conflicts of interest regarding the publication of this paper.

\section{References}

[1] Chen, D.F., Li, J.S., Yang, Y.X. and Guo, M. (2020) Study on the Application Value of Thalassemia Gene + Hemoglobin Electrophoresis in the Pre-Pregnancy Diagnosis of Thalassemia. Heilongjiang Medicine, 44, 955-957.

[2] Zhuang, Q.M., Liu, X.L., Huang, H.L., Wang, Y.B., Zhuang, J.L., Xu, L.P. and Hong, G.T. (2021) Comparison of the Application Effects of 4 Thalassemia Screening Modes. Laboratory Medicine, 36, 173-176.

[3] Su, P., Zhou, Q.L., Wang, L.F., Lou, J., Cai, W.L., Lu, R.L. and Sun, X. (2021) Analysis of Mutation Types of Thalassemia Genes in Xiaoshan Area of Hangzhou. Zhe jiang Medicine, 43, 401-404.

[4] Li, Y.M., Cai, Q.Q., Qin, J.L., Jin, X., Chen, Y.Q., Mo, Y.J., Li, Y. and Zhang, X.M. (2021) Analysis of the Genotypes and Phenotypes of Three $\beta$-Deletion Thalassemias. Laboratory Medicine, 36, 642-645. 
[5] Huang, S.J., Chen, W.L., Zhuang, J.L., Zhuang, Q.M., Zeng, J.X. and Wang, Y.B. (2021) Gene analysis of Alpha and Beta Thalassemia in Children in Quanzhou, Fujian, China. Chinese Journal of Experimental Hematology, 29, 1266-1270.

[6] Liu, L., Yu, C.R., Li, S.S., Dai, H.J., Yuan, Y. and Cao, P.J. (2021) Analysis of Erythrocyte Parameters, Hemoglobin A2 and Gene Detection Results in 709 Cases of Alpha Thalassemia Gene Carriers. Guangdong Medicine, 42, 1006-1008.

[7] Zhao, H.Y., Ye, Q., Wang, H.X. and He, Y.F. (2021) Analysis of Genetic Testing Results of 141 Patients with Alpha Thalassemia in Honghe Prefecture, Yunnan Province. Chinese Journal of Experimental Hematology, 29, 596-602.

[8] Lu, H., Qin, Q., Li, J.H., Chen, T., Liang S.J. and Lu, X.S. (2021) Retrospective Analysis of Gene Diagnosis of Thalassemia in Baise Area of Guangxi. Chinese Journal of Experimental Hematology, 29, 865-868.

[9] Xiang, X.H., Leng, J., Wang, D., Mo, L.J., Jiang, W. and Wei, C.D. (2021) Analysis of Gene Defects of Thalassemia in Lingui Area of Guilin. Chinese Journal of Experimental Hematology, 29, 860-864.

[10] Yang, M., Li, C.Y., Lei, D.Z. and Zhang, H.Q. (2021) Application of High-Throughput Sequencing Technology in 11212 Pregnant Women Thalassemia Gene Screening in Suxian and Beihu Districts of Chenzhou City, Hunan Province. Chinese Experimental Hematology Magazine, 29, 188-192.

[11] Pan, X.L., Bao, Y.W. and Pan, S.Q. (2021) Analysis of Gene Mutation Types in 507 Cases of Thalassemia. Modern Practical Medicine, 33, 190-191.

[12] He, D., Gu, H.Y., Zhang, H.Y., Wang, W. and Wang, X.Y. (2021) Analysis of the Results of Thalassemia Gene Detection in the Population of Tujia and Miao Nationalities in Chongqing. Chinese Journal of Endemiology, 40, 109-113.

[13] Li, L., Luo, G.X., Li, L.X. and Xiao, Q.Z. (2021) Analysis of the Results of Thalassemia Gene Detection in Zhuhai Area. Hainan Medicine, 32, 88-90.

[14] Zou, L., Chen, S.H., Xie, W.X., Huang, Z.Q., He, C.Y. and Jian, Y.F. (2020) Analysis of Rare Thalassemia Genotypes and Phenotypes in Foshan, Guangdong. Chinese Journal of Endemiology, 39, 791-795.

[15] Hu, X.N., Ou, W.Y., Ouyang, H., Liu, D.X., Xu, W.H., Luo, W.P. and Long, H. (2020) Analysis of 2659 Cases of Thalassemia Gene Detection Results. Chinese Journal of Eugenics and Genetics, 28, 1174-1176+1193.

[16] Zeng, Y.Z. (2020) Genetic Detection and Analysis of $\alpha \beta$ Complex-Thalassemia in Children in Yangjiang City. Experimental and Laboratory Medicine, 38, 1013-1015.

[17] Yang, F.F., Gao, W.H., Liang, L.S., Xie, Y.N., Xia, L.H., Huang, G.Q. and Lv, F.B. (2020) Analysis of Gene Detection Results of 301 Thalassemia in 9236 Pregnant and Lying-In Women in Foshan City. Journal of Molecular Diagnosis and Therapy, 12, 1147-1151.

[18] Shang, C.Y. (2020) The Latest Survey of the Distribution of Thalassemia Genotypes in Guangzhou Area and the Establishment of Differential Screening Equations. Guangzhou University of Traditional Chinese Medicine, Guangzhou.

[19] Yang, R.Y., Hu, K.M., Chen, Y.Z. and Liu, J.X. (2020) Analysis of Thalassemia Gene Mutation Types in 3106 Pregnant Women in Longhua District, Shenzhen. Chinese Journal of Eugenics and Genetics, 28, 914-916+957.

[20] Chen, Y.J., Tang, L.Y., Wei, Y.S., Wei, L.L. and Xie, D.N. (2020) Screening of Thalassemia and Genetic Analysis of 16,111 Infertility Patients in Guangxi. Guangxi Medicine, 42, 1869-1874.

[21] Li, D.M. and He, S. (2021) Analysis of the Gene Types of Thalassemia in 30417 Children. Chinese Journal of Contemporary Pediatrics, 23, 841-847. 
[22] Lin, M., Ou, Y.X. and Chen, S.X. (2020) The Effect of Thalassemia Gene Diagnosis on Pre-Pregnancy Eugenics. Chinese Maternal and Child Health Care, 35, 2284-2286.

[23] Ju, A.P., Liu, Y.X., Lin, K., Meng, X.R., Li, X.C., Wei, G.X. and Liu, S.X. (2020) The Genotype and Hematological Characteristics of $\alpha \beta$ Complex Thalassemia in Northern Guangzhou. Chinese Electronic Journal of Diagnostics, 8, 121-125.

[24] Zhong, Y.H., Ye, L.X., Cai, X.J., Xie, C.L. and Chen, J.G. (2020) Gene Characteristics and Change Trend of Thalassemia in Neonates in Dongguan Area. Chinese Journal of Contemporary Pediatrics, 22, 454-459.

[25] Chen, D.M. (2020) 5488 Cases of Common Thalassemia Gene Analysis and Rare Hong Kong Type Thalassemia Genotype Identification. Southwest Medical University, Luzhou.

[26] He, J.P., Lu, M.X., Zou, J., Lu, Y., Sun, Y.B., Qian, Y., Huang, S.D. and Tang, J. (2020) Analysis of Neonatal Hemoglobin Screening and Thalassemia Gene Detection Results in Kunming Area. Chinese Journal of Eugenics and Genetics, 28, $412-414+476$.

[27] Wang, W.M., Ma, L., Zhou, J. and Chen, L. (2020) The Application Value of Self-Made Compound Quality Control Products in the Detection of $\alpha$ and $\beta$-Thalassemia Genes. Laboratory Medicine and Clinics, 17, 899-901+905.

[28] Zhang, W.X., Yu, T., Sun, N., Gao, F., Huang, J. and Qu, S.F. (2020) Quality Analysis of the Thalassemia Gene Detection Kit. Journal of Molecular Diagnosis and Therapy, 12, 279-282+304.

[29] Long, J. (2020) Alpha-Thalassemia Gene Carrying Status and Hotspot Mutation Detection Range in the Population of South Guangxi. Guangxi Medicine, 42, 457-460.

[30] Long, L., Yang, B., Hou, X.L. and Fu, M. (2020) Analysis of Thalassemia Gene Types in People of Childbearing Age in Qiandongnan Area of Guizhou. Chinese Journal of Eugenics and Genetics, 28, 19-20+36.

[31] Cai, W.Q., Hu, X.J., Dai, X. and Xiong, Q. (2019) Gene Detection and Prenatal Diagnosis of Thalassemia in Pregnant Women in Wuhan, China. Chinese Journal of Experimental Hematology, 27, 1919-1924.

[32] Liu, Q., Jia, Z.J., Xi, H., Liu, J., Peng, Y. and Wang, H. (2019) Analysis of the Mutation Types of Thalassemia Genes in 5018 Cases in Hunan Area. Chinese Journal of Experimental Hematology, 27, 1938-1942.

[33] Liu, F.Z., Zhong, H. and Mai, F.J. (2019) Analysis of Prenatal Genetic Diagnosis of Amniotic Fluid in 687 Patients with the Same Type of Thalassemia. Clinical Research of Chinese Medicine, 11, 121-123.

[34] Long, L., Yang, B., Hou, X.L. and Fu, M. (2019) Analysis of the Results of Gene Diagnosis of Thalassemia in Southeast Guizhou. Chinese and Foreign Medical Research, 17, 50-52.

[35] Zhu, X.J., Wang, X., Liu, L.J., Liu, L.M., Yu, X.Y., Cai, L. and Wu, X.J. (2019) Analysis of Rare Thalassemia Gene Mutations and Prenatal Diagnosis in Hakka Population in Huizhou Area. China Maternal and Child Health Care, 34, 4987-4990.

[36] Huang, G., Li, Z.H., Zheng, Y.W., Wu, J. and Liu, S.N. (2019) Gene Identification and Analysis of Chinese Type $\sim \mathrm{G} \gamma \sim+(\sim \mathrm{A} \gamma \delta \beta) \sim 0$ Thalassemia in Guangdong. Clinical Blood Transfusion and Laboratory, 21, 465-468. 